\title{
Gestures, Embodiment, and Learning the Rate of Change
}

\author{
Yanning $\mathrm{Yu}$ \\ David H. Uttal
}

Northwestern University

\section{Author Note}

This research was supported by the NSF-funded Spatial Intelligence and Learning Center, Award \#SBE-1041707.

We have no known conflict of interest to disclose.

Correspondence concerning this article should be sent to Yanning Yu, 108 Ashlar Ct, Cary, NC 27519. Email: yanningyu@gmail.com 


\begin{abstract}
Many researchers have stressed the embodied nature of mathematical understanding. Here we explore how embodied knowledge may evolve as students learn a basic calculus concept: the rate of change. We examined undergraduate students with different levels of calculus knowledge working in pairs to model the rate of change in an everyday phenomenon. Our findings revealed substantial differences between advanced and introductory students in how they represented rate of change with their speech and gestures. In particular, the advanced students' embodied representations showed alignment with the formal symbolic process of integration and reflected more advanced ways to coordinate the relation between multiple changing variables. For example, advanced students often made gestures that represented a "disk" when explaining how the rate at which water rose in a bottle was related to the change in height. Thus, both introductory and advanced students demonstrated embodied knowledge through speech and gestures, but the advanced students constructed different concrete representations that reflected an advancement in their embodied knowledge. Our findings are relevant to calculus education and to the study of gestures in mathematics learning.
\end{abstract}

Keywords: gesture, calculus, embodiment, representation 
The notion that mathematical ideas are grounded in embodied interactions is one of the most influential ideas in mathematics education today (Nemirovsky et al., 2013; Radford, 2014). Since Bruner (1966) and Piaget (1977), numerous studies have shown that learners develop abstract mathematical understanding from interacting with objects in the world. Lakoff and Núñez (2000), for example, argue that even the most abstract symbolic understandings are developed through conceptual metaphors which are grounded in bodily interactions with the world. The embodied understanding constitutes an essential part of mathematics and may still play an irreplaceable role even in expert mathematicians' novel problem-solving practices (Wilkerson \& Wilensky, 2011). Tall (2004) points out not only that many symbolic concepts arise from natural embodiment rooted in experiences with the physical world, but also that embodied knowledge may be further developed through learning symbolic procedures, and grow into more sophisticated formal ideas (Gray \& Tall, 2001).

Here we focus on one important aspect of embodied cognition in mathematics: the role of gestures in advancing embodied understanding. Studies have shown that teachers' instructional gestures can facilitate students' learning (Alibali \& Nathan, 2012). Learners' own gestures have been found to support mathematics learning as well (Cook \& Goldin-Meadow, 2006; Kim et al., 2011). Their gestures may indicate learning of new concepts not yet formed in speech (Alibali \& Goldin-Meadow, 1993; Church \& Goldin-Meadow, 1986; Goldin-Meadow, Alibali, \& Church, 1993) and instigate the creation of novel ideas during problem solving (Goldin-Meadow, Cook, \& Mitchell, 2009). Researchers are exploring how gesture and speech interact, and how this interaction may relate to the learner's underlying thought processes. Some argue that gestures emerge from perceptual and motor simulations that underlie embodied language and mental imagery (Hostetter \& Alibali, 2008), and therefore reflect learners' mathematical ideas; at the 
same time, gestures may also influence mathematical thought because seeing and making gestures can simulate mental objects and actions that influence perception, which in turn influences thought (Alibali \& Nathan, 2012; Goldin-Meadow \& Beilock, 2010). In sum, gestures may play a role in shaping and advancing learners' thought processes that give rise to deep conceptual understanding of mathematics ideas, including those associated with complex symbolic operations.

Prior research on gestures and embodied mathematics has often focused on younger students learning mathematics topics such as arithmetic (Broaders et al., 2007), fractions (Edwards, 2009), and Cartesian graphs (Bjuland et al., 2008; Radford, 2009; Reynolds \& Reeve, 2002). Here we build on current research by empirically investigating the relationship between gestures and thought processes underlying the learning of a more advanced math topic, rate of change, one of the most fundamental concepts in calculus.

We draw on existing calculus learning literature (Carlson, et al., 2002; Castillo-Garsow, 2012; Castillo-Garsow et al., 2013; Thompson \& Carlson, 2017) to identify critical conceptual developments that are involved in learning the rate of change. This analysis then guides our investigation of ways in which gestures may reflect and influence thinking about the rate of change (Marghetis \& Núñez, 2013; Walkington et al., 2014; Yoon et al., 2011). We investigate the characteristics of gestures that may support grounding of the rate of change concept by examining how undergraduate students use gestures to explain rate of change in an everyday phenomenon. We suggest that there might be some critical affordances of gestures that may help learners to advance their embodied understanding of rate of change and apply it to everyday phenomena. 


\section{What is Learned in Learning the Rate of Change?}

Calculus, and rate of change in particular, is an essential tool for understanding dynamic events in the world and for modeling them symbolically. The learning of rate of change involves not only manipulating abstract symbols, but also being able to meaningfully relate those symbolic elements and procedures with their embodied understanding, so that the learners may develop a more complex approach to model and explain concrete dynamic events in the real world.

The embodied cognition perspective suggests that the knowledge of rate of change is grounded in everyday experience. To illustrate what initial embodied knowledge is useful for understanding the rate of change, and how the embodied knowledge might advance in the process of learning the rate of change, we use the example of a driver applying the brake when approaching a stoplight. A new driver quickly learns when to apply the brake as they approach a stationary car. This decision involves considering the current speed of the car, the anticipated rate of change (deacceleration) after the brake is applied, the force with which the brake will need to be applied, and the anticipated stopping distance. This problem clearly involves, at some level, thinking about the rate of change of the car's velocity. But the driver does not have to perform a calculus problem on paper to figure out when and how hard to apply the brake.

As rich as the initial embodied knowledge is, learning calculus still requires developing a more complex way to conceive rate of change in the world. Two important aspects of conceptual development have been identified as crucial to understanding the rate of change (Thompson \& Carlson, 2017). The first development concerns variational reasoning - how learners develop a more complex way to conceive the change within one variable. In the example of applying a brake to stop a car, the driver may initially conceive of the speed change of the car as decreasing 
generally. But after learning calculus, they may be able to think of rate of change in a new way, such as by finding how much decrease in speed occurred per second or per distance travelled. Castillo-Garsow and colleagues (2012) refer to this way of thinking about change by units as having a "chunky image of change".

As learners continue to advance their calculus knowledge, they might begin to think of speed change in terms of infinitesimally small intervals and realize that there is smooth and continuous speed change within these intervals. This way of thinking is classified as having a "smooth and continuous image of change" (Castillo-Garsow et al., 2012). The advancement from a "chunky image of change" to "smooth and continuous image of change" to conceive the rate of change is a major conceptual development in the process of learning calculus.

The second conceptual development concerns covariational reasoning (Thompson \& Carlson, 2017) - how learners envision the process of which a variable's quantity varies in relation to another variable. Carlson and colleagues (2002) highlight a key advancement in covariational reasoning as a transition from coordinating the average rate of change of the dependent variable with uniform increments of change in the independent variable, to coordinating the instantaneous rate of change of the dependent variable with continuous changes in the independent variable. In the case of driving, the learner might initially conceive of a general relation between speed and the force on the brake - the speed decreases as the force increases. However, as the result of learning calculus, the learner might begin to conceive an instantaneous speech change in relation to an infinitesimal change in the force on the brake, thus developing a more complex way to model the speed change, taking into account the changes in co-varying variables. 
In summary, researchers have identified two types of conceptual developments which are critical to learning the rate of change, including an advanced way to conceive change within one variable and an advanced way to coordinate changes between covarying variables. Next, we examine literature on gestures and mathematics learning to examine features of gestures which may potentially support embodying those advanced conceptions of the rate of change.

\section{Gestures in Learning the Rate of Change}

The research on calculus conceptual developments has specific implications for exploring the role of gestures in learning the rate of change. First, gestures may reflect and influence the conceptual advancement in variational reasoning. Since gestures may influence thought (Alibali \& Nathan, 2012; Goldin-Meadow \& Beilock, 2010), gestures may evoke certain mental imageries or simulated actions that foster an advanced conception of change within one variable. For example, learners who initially had a "chunky" image of change might enact a "smooth and continuous" image of change (Castillo-Garsow, 2012; Castillo-Garsow, Johnson, \& Moore, 2013) through their gestures in reasoning about rate of change in an everyday context, and therefore facilitate their variational reasoning. Marghetis and Núñez (2013) indicate that dynamic gesture may reveal learners' dynamic conceptions of calculus. In their study of experts' gestures during an advanced calculus task, they found that the experts predominantly used dynamic rather than static gestures to reason with calculus functions that involved dynamic conceptualizations, such as the concepts of "increasing" functions and "continuity". They also found that the experts' gestures were not entirely determined by the content of their speech; experts could use gestures to convey ideas not fully expressed in written or spoken forms, including dynamic conceptions that are central to the rate of change. Inspired by their study, we suggest that dynamic gestures may also reflect learners' variational reasoning, because learners' conceptions 
of change within one variable, such as a "chunky image of change" and a "smooth and continuous image of change", may be considered specific dynamic conceptions of rate of change.

Second, dynamic gestures might also facilitate covariational reasoning - coordinating the change in one variable in relation to another variable. Walkington et al. (2014) studied the use of static and dynamic depictive gestures in geometric proving tasks. They found that while static depictive gestures represent a static, single object that is not interacting with other objects, dynamic depictive gestures allow problem-solvers to engage in fluid transformations of the objects with their body and thus facilitate geometric proof and justification. For example, learners might represent a static object with hands, and then move hands outwards and inwards to show the object growing or shrinking, or they might modify one element of an object to test impact on the rest of the object. We suggest that the affordances of dynamic depictive gestures in making geometric proofs may apply to covariational reasoning in calculus as well, because both types of reasoning concern the relation between multiple objects or variables. Learners could potentially use dynamic depictive gestures to represent an instantaneous change in a variable and relate the change fluidly with continuous changes in another variable, in the same way as transforming an object to test impact on the rest of the object for geometric proofs.

Furthermore, Yoon et al. (2011) show that gestures played a role in incorporating formal mathematical ideas with ways of thinking about dynamic events in the world. They examine how calculus meanings became endowed and signified during a modeling activity as two mathematics teachers constructed an anti-derivative graph together. Through their gestures, the problemsolvers connected their embodied knowledge of steepness associated with hill climbing with mathematical concepts such as continuity, concavity, gradient, and point of inflection. In 
addition, Yoon et al. suggest that gestures may encourage learners to experiment with new ideas as they work on modeling the rate of change in an everyday context. Our study will build on these studies and further explore whether and how the characteristics of dynamic gestures, along with other features of gestures, may support learning and reasoning with the rate of change.

\section{The Present Study}

We examined undergraduate students' underlying conceptions of the rate of change, by exploring their gestures used to describe and explain rate of change to a partner. We draw on mathematics learning research on the conceptual development concerning the rate of change (Carlson, et al., 2002; Thompson \& Carlson, 2017) to analyze whether and how the characteristics of speech and gestures might indicate the participants' underlying conceptions of the rate of change. We also draw on research regarding gestures and mathematical reasoning (Marghetis \& Núñez, 2013; Walkington et al., 2014; Yoon et al., 2011) to examine features of gestures that might facilitate reasoning with the rate of change.

We presented ten dyads of undergraduate students with a familiar everyday problem and asked them to collaboratively model rate of change in that context. Building on theories which suggest that gestures might reflect and influence thought (Hostetter \& Alibali, 2008; Alibali \& Nathan, 2012; Goldin-Meadow \& Beilock, 2010), we hypothesize that in this paired problemsolving setting, the students' speech and gestures may uncover their underlying thought processes and even create opportunities for them to generate new ideas as they work together to model the rate of change regarding a concrete phenomenon.

Each dyad consisted of an introductory-level student and a more advanced partner who had taken three or more calculus-related courses in college. Rather than putting students with similar calculus knowledge together, we chose this mixed pair composition with the intention to 
find a range of different gestures naturally emerging from the pairs' problem solving, which may reveal differences in their thought processes regarding the rate of change. By exploring the differences in the gestures and thought processes from students with different levels of calculus knowledge, we intend to find important embodied ways of thinking that are critical to advancing learners' conceptual understanding of rate of change.

This pair composition was in part inspired by the idea that speakers are likely to gesture about information that is particularly newsworthy to the ongoing discourse-information that contrasts with information already present (McNeill, 2005), and that gestures are influenced by what the listeners do and do not know (Gerwing \& Bavelas, 2004; Holler \& Stevens, 2007). This suggests that the pairs in our study might potentially produce a dense concentration of gestures around where they reason about rate of change differently. Moreover, since seeing the speaker's gesture may help the listener comprehend the speaker (Alibali \& Hostetter, 2010; Cook \& Tanenhaus, 2009), this mixed pair setting was also intended to shed some light on the affordances of gestures in supporting the learning of rate of change.

\section{Method}

\section{Participants}

The study was conducted at a highly selective university in the Midwest. Twenty participants were recruited from an Introductory Psychology class with a required research participation requirement. Students received credit toward the completion of this requirement for participating in our research. Students with a wide range of calculus knowledge take introductory psychology, and thus this pool of potential participants provided us with the needed variability in calculus knowledge. We selected 10 advanced students who had completed three or more calculus courses, and 10 introductory-level students who either had completed one college-level 
calculus course or had taken one calculus course in high school and were enrolled in a collegelevel calculus course at the time of recruitment. All participants had some formal exposure to calculus even though their levels of expertise differed.

\section{The Setting}

Participants worked in pairs to solve three calculus problems in an empty classroom. The problems were presented on a whiteboard, one at a time, following a fixed order. The first was a warm-up problem that asked participants to draw the derivative graph based on the graph of a function given to them. This was a simple problem designed to familiarize the participants with the setting and refresh them with the concept of rate of change. The main problem of our study was presented as the second problem, which asked participants to model a bottle-filling activity by graphing the rate of change. A more detailed description is provided in the next section. The third problem asked participants to write an integral function to describe the volume of a pyramid. The third problem was intended as a transfer problem which was related to the volume of the bottle in problem two. Here we only focus on discussion the second problem to address the research purpose of this study. The participants were encouraged to think aloud and collaborate with their partners in solving the problems. A camera is set in the classroom to record their problem-solving process. Each session lasted 40-50 minutes.

We intentionally framed the problem-solving activity as collaborative rather than instructional. Although the pairs had mixed levels of prior knowledge, we did not inform the participants about their differences and urged them to collaborate. In addition, we selected problems that were non-trivial to the more experienced participants but approachable by the introductory-level participants, so that both participants could contribute to the problem-solving; 
our goal was to avoid having the advanced student teach or lecture the introductory student, but rather to have the two students work together to solve the problem.

\section{Procedures}

Here we give a detailed description about our main problem of investigation. Participants were presented with a diagram of a funnel-shaped container on the white board (see Figure 1) and were told that water was being added into the container at a constant rate $(\alpha \mathrm{ml} / \mathrm{s})$. They were asked to graph the height of water in the bottle as a function of time and the rate of change of height as a function of time. That is, $h(t)$ and $h^{\prime}(t)$.

This problem was an adaptation from a well-known rate of change problem, the bottlefilling problem (Bell \& Janvier, 1981; Carlson, et, al., 2002). We chose this problem because it concerns a concrete familiar activity_pouring water into a container. Therefore, by asking this everyday problem, we anticipate that the participants would produce many gestures along with speech to represent some aspects of this concrete familiar activity, which might reveal their embodied understanding of rate of change.

Building on the original problem, we extended the problem so that it would require deeper insight about rate of change, and thus non-trivial for undergraduates who had some formal exposure to calculus. Specifically, we asked the participants to graph not only the height $h(t)$ but also its derivative h'(t), the rate at which water level increases with time. Consequently, they need to go beyond intuitively conceiving the rate of change in terms of going "faster" or "slower", "increasing" or "decreasing". Instead, they need to coordinate the relation between multiple variables: the volume of water being added into the container per second, which is a constant $(\alpha \mathrm{ml} / \mathrm{s})$, and the change in the container's volume with every small increase in height; 
this value remains a constant within the cylindrical section but increases quadratically with height in the conical section.

During the problem-solving process, the experimenter provided explanations to the problems when being asked and occasionally interacted with the participants by asking follow-up questions like "can you say more about why __?" to prompt the participants to clarify their thought processes. Once the participants produced one of the three typical h'(t) graphs (see Figure 2), the experimenter presented them with the other two graphs and asked them to choose which one was accurate and explain why, regardless of whether they made the correct choice initially. This step was intended to allow the participants to externalize their reasoning as much as possible and potentially use more than one strategy. For example, they could either formulate and solve calculus functions or make concrete representations that show how the variables are related. Successfully conceptualizing and coordinating the multiple variables in the problem will lead to finding the $h^{\prime}(t)$ to be steady in the cylindrical section and decreasing in the conical section as shown in Figure $2 b$.

\section{Results}

\section{Approach to Data Analyses}

We used the video coding software Studiocode to facilitate our data selection and coding. The software allowed us to code the videos directly on a timeline, so that we could extract distinctive acts of speech and gestures from different individuals within a short period of time, while attending to the sequences in which those acts unfolded. Using the software, we categorized each participant's strategies into data segments, coded speech and gestures based on their characteristics, and conducted fine-grained analyses on selected data segments of the participants' interactions. 
We approached the video analysis with three guiding questions: 1) In what ways did the speech and gestures of the advanced participants differ from those of the introductory participants? 2) What do the differences in the introductory and advanced participants' speech and gestures suggest about differences in their conceptions of the rate of change? 3) How did different gestures emerge from the pairs' problem-solving process? Answering these questions will help us understand the participants' underlying conceptions about rate of change and the affordances of gestures which may facilitate communicating and advancing one's ways of thinking about the rate of change. We report on the coding and results for each question separately.

\section{Question 1: In what ways did the speech and gestures of the advanced participants differed} from those of introductory participants?

To address this question, we categorized the participants' strategies used to solve the problem. While all ten pairs accurately described the $\mathrm{h}(\mathrm{t})$ graph as increasing linearly at first and then smoothing out as a curve, they encountered considerable difficulty with the h'(t) graph, which led them to use multiple types of strategies. Because our primary concern was the role of gestures in reasoning about the rate of change, we examined whether and how gestures were used in carrying out each type of strategy and how the use of gestures might differ among the two groups of participants.

\section{A) Categorizing Strategies}

We identified three types of strategies that the participants used to find the rate of change: concrete representational, graphical, and equational. Table 1 provides detailed examples for each type of strategy, with examples from speech and descriptions of gestures. The concrete representational strategy involved modeling the process of water rising in the bottle with speech 
and gestures, such as representing the shape of the bottle and simulating water rising in the bottle with varying speed. The graphical strategy involved reasoning with graphs, such as finding the $h^{\prime}(t)$ based on the gradients at multiple points or segments of the $h(t)$ graph. The equational strategy involved the use of formal symbolic functions, such as writing out the volume equation of a cone, and subsequently taking its derivative.

\section{Findings from the Categorization of Strategies}

As the problem itself was graphical, all but one introductory participant used a graphical strategy. Nevertheless, most participants also used other strategies. As would be expected, more advanced participants ( 8 out of 10) used equational strategies than introductory participants (4 out of 10). Although the advanced participants used more formal equational strategies, this did not reduce their use of concrete representational strategies. In fact, 9 advanced participants also used concrete representational strategies, while 7 introductory participants used those strategies.

The role of gestures in each strategy. When participants used an equational strategy, they rarely gestured. We found three ways in which participants used gestures within a graphical strategy: 1) they often used pointing gestures to refer to the linear part and the curve part of the $h(t)$ graph when drawing the h'(t) graph (see Table 1 graphical strategy for example); 2) some referred to those parts of the h'(t) graph by directly gesturing a linear line or a curve; 3) some gestured linear lines to represent the gradients at different locations of the $h(t)$ graph to help finding the rate of change h'(t). Because these gestures were used to refer to and extract information from the graphs, these gestures were not directly related to the depiction of the realworld situation this problem addressed (i.e., pouring water into a container). In addition, because we did not find major differences between the introductory and advanced participants in how they used pointing gestures or in how they represented gradients with their gestures, those 
gestures did not show whether and how different levels of calculus knowledge might influence students' ways of conceiving the rate of change in this familiar context.

In contrast, we found that the concrete representational strategies often involved the use of gesture in the formation of conceptual structures. As we show in the next section, there were important differences in how the two groups of participants used speech and gestures within concrete representational strategies. These speech and gestures revealed different ways of thinking about rate of change in the real-world situation, which can be related to different levels of developments in variational and co-variational reasoning (Thompson \& Carlson, 2017). Therefore, by examining the differences in the participants' concrete representational speech and gestures, we might understand whether participants with different levels of calculus knowledge have different conceptions about rate of change.

Moreover, the concrete representational strategies involved simulations of actions (e.g. cutting, slicing, and accumulating) and visual images (e.g. an image of a "disk") that were related to problem context. Prior research on embodied learning of mathematics indicates that learners might intentionally produce representational gestures to simulate actions and images of mathematical objects to facilitate thinking and communication (Alibali \& Nathan, 2011). Therefore, we conducted a subsequent analysis on the concrete representational strategies in order to explore the potential affordances of representational gestures for communicating and reasoning about the rate of change and to examine whether and how introductory and advanced participants might leverage those affordances differently.

\section{B) Characterizing Concrete Representations}

Coding. We used idea units (Chafe, 1979; 1980) as the unit of analysis to examine more closely the various kinds of concrete representations formed in speech, in gesture, or in both. 
Speech and gestures both play significant roles in conveying ideas grounded in actions and perceptions, but they may sometimes convey different meanings (Alibali \& Nathan, 2012). Therefore, we coded speech and gestures separately.

An idea unit in this context represents the expression of a concrete representational model that explains the rate of change. One unit would end when a new object or movement was introduced, or when the individual had finished conveying an idea. An individual could generate more than one unit of concrete representation. Through an initial round of coding, we found two basic elements that constitute a concrete representational model: 1) The object of change-a referent object chosen by a participant to describe what was changing in a dynamic event, often a unit quantity or shape (e.g., the round-shaped cross-sections of the bottle, also referred to as the "area", which represented a small change in the amount of water at that height); 2) The process of change - the process chosen to model how the object was changing (e.g., whether it was changing steadily or in relation to another variable). We subsequently coded different types of objects and processes depicted in speech and in gestures by each participant.

Next, we present an excerpt to illustrate these two aspects of a concrete representational model. The parts of speech and gestures representing an object of change and a process of change were underlined.

\section{Excerpt 1}

Introductory: This one [pointing to the first part of their $\mathrm{h}(\mathrm{t})$ graph], it has [verbal pause while hands making a round funnel shape; see Figure 3] a smaller capacity to hold, like a smaller volume.

Advanced: It is constant rate.

Introductory: Right, it is constant. 
Advanced: Like, each slice is the same [hand showing multiple horizontal cutting actions while moving up in a discrete manner; see Figure 4]. And that's why the derivative is like that [pointing to the linear part of $\left.h^{\prime}(t)\right]$.

In Excerpt 1, the two participants used different terms to represent the object of change“capacity", "volume", and "each slice"; their gestures also depicted different shapes of objects (see Table 2). Different processes of change were reflected in their gestures as well. While the introductory participant's gesture was static, the advanced participant demonstrated dynamic and discrete movements with his hands to show the process of change. Through multiple passes of coding, we identified three types of objects of change and three types of processes of change (see Appendix for the structure of codes).

Objects of Change. We identified three categories of object of change to encompass all the referent objects selected by the participants to represent what is changing: "radius", "slice", and "funnel". Each category included similar words or gestures that expressed the same meaning. Table 2 provides definitions of each category with examples in speech and gesture.

Process of Change. We identified three types of processes of change that participants used to depict the varying speed of the rising water or the varying capacity of the bottle as the water rose. These categories included static, continuous, and recursive. Continuous and recursive refer to two different types of dynamic gestures representing the process of change. Table 3 provides definitions and examples in speech and gestures.

Interrater Reliability. After developing and refining the coding scheme, two coders separately coded all the concrete representations by object and process. Speech and gestural representations were coded independently. The interrater reliability between the first and the second coder was 78\%. The differences were later compared and resolved. 


\section{Finding from the Categorization of Concrete Representations}

The introductory and advanced participants used very distinctive concrete representations to model water rising in the bottle. We counted the number of times each type of object and process of change appeared in each individual's concrete representations. Differences were found in both how they represented the object of change and in how they represented the process of change.

Differences in Representing the Object of Change. Table 4 is the summary of the occurrences of speech and gestures that represented three types of objects of change, produced by 7 introductory and 9 advanced participants who used the concrete representational strategy.

In total, the advanced participants produced more concrete representations than did the introductory participants. The total number of representations made with gestures was similar to the total number of representations made in speech. This suggests that most participants (introductory and advanced) produced gestures along with their speech when using a concrete representational strategy.

Next, we examined whether the introductory and advanced participants differed in how they depicted the objects of change. We first calculated each individual's proportions of concrete representations that fall into each object category ("radius", "disk", and "funnel"). For example, if a participant represented three objects of change, one coded as radius and two coded as disk, the participant' proportions would be $0.33,0.67$, and 0 , respectively. We then calculated the average proportions of representations in each category for both groups. Analyses were conducted for speech and gestures independently. We found significant differences between the introductory and the advanced participants in both their speech and gestures representing the object of change. 
Figure 5 shows the two group's average proportions of speech representing "radius", "disk", and "funnel". The difference between the two groups was significant, $\chi^{2}(2, N=34)=$ $18.47, \mathrm{p}<.01$. Figure 6 shows the average proportions of gestures used to represent the three types of objects. The difference was also significant, $\chi^{2}(2, \mathrm{~N}=35)=11.29, \mathrm{p}<0.01$.

As Figure 5 and Figure 6 made clear, the most distinctive difference between the two groups was in the use of a "disk" to model what is changing. The advanced participants most frequently (0.77) used a "disk" in their speech, which describes the surface area of water at any given height, in order to represent a small change in the amount of water at that particular height. They also frequently (0.75) used gestures to represent a "disk" (see Table 2 for gesture images).

In contrast, the introductory participants described a "disk" in their speech much less frequently (0.05). Instead, they primarily (0.62) used terms such as "container", "funnel”, "shape", and "space" to refer to the overall (or otherwise unspecified) shape of the container. For gestures, the introductory-level participants primarily (0.68) made gestures describing the overall funnel-shaped container: using two hands to show a space with a wide opening (e.g., a V-shape).

Still, some introductory participants represented a "disk" with gestures more frequently (0.25) than they did in speech (0.05). This difference was also reflected in Table 4, which showed 4 incidents where an introductory participant gestured a "disk" but only 1 such instance found in their speech.

Differences in Representing the Process of Change. Table 5 is a summary of the occurrences of the three types of speech and gestures representing the process of change, produced by the 7 introductory and 9 advanced participants who used the concrete representational strategy. 
Again, we analyzed how the two participant groups represented the process of change differently by comparing their average proportions of representations under the three categories of processes (static, continuous, and recursive). We found significant differences between the two groups in how they represented the process of change, through both speech and gestures.

Figure 7 displays the average proportions of speech representing the three types of processes. The difference between the two groups was significant, $\chi^{2}(2, \mathrm{~N}=34)=13.64, \mathrm{p}<$ 0.01. Figure 8 displays the average proportions of gestures used to represent the three types of processes. The difference was also significant, $\chi^{2}(2, \mathrm{~N}=35)=9.04, \mathrm{p}<0.05$.

The advanced participants primarily ( 0.78 of speech and 0.69 of gestures) represented the process of change as small and consecutive increments, which we coded as recursive. For example, they often highlighted a small change in the amount of water, using terms like "disk", and connected that change with a small increase in height, using terms such as "each height" and “every increase in height". Likewise, in gestures, they often made a circle horizontally with the thumbs and index fingers to represent a "disk", and then expanded the circle while simultaneously raising both hands, in a discrete manner (see Table 3, recursive gestures).

In contrast, the introductory participants primarily represented the process as continuous ( 0.71 of speech and 0.57 of gestures). For example, the introductory participants often used terms like "higher and higher" and "more and more" to indicate an overall smooth and continuous trend, without specifying any intervals or relating the changes in one variable with other variables. Their gestures also represented an overall smooth and continuous trend; they did not often use a series of repeated gestures to signify intervals within the overall smooth and continuous trend. 


\section{Summary of Representational Differences}

The advanced participants produced more concrete representations than the introductory participants did when modeling the rate of change. The content of their concrete representations also differed. The concrete representations made by the advanced participants most often involved representing (in speech, gesture, or both) a "disk" and a recursive process of change. They constructed a dynamic representation of the volume of water in the bottle as many thin disks that were being stacked up. In contrast, the introductory participants were more likely to describe a smooth and continuous trend without specifying any intervals within the overall smooth and continuous trend. The pattern we found in gestures was similar to the pattern we found in speech. Moreover, we found that 8 out of the 9 advanced participants and all 7 introductory participants who engaged with concrete representational strategies in their speech also produced representational gestures. Therefore, gestures might play a significant role in the pairs' thought processes of creating a concrete representational model to explain the rate of change.

Question 2: What do the differences in the introductory and advanced participants' speech and gestures suggest about differences in their ways of reasoning about the rate of change?

We applied two lenses to address this question. First, we examined whether and how the features of the participants' concrete representations might be informed by their formal knowledge of calculus, specifically, the procedures of integration. Second, we drew on research concerning the conceptual development in ways of reasoning with co-varying quantities (Carlson, et al., 2002; Johnson, 2012; Thompson \& Carlson, 2017) to examine the link between the participants' distinctive concrete representations and their different ways of reasoning with the rate of change. The analyses shed light on some important differences between the 
introductory and the advanced participants that support Thompson and Carlson's theory (2017) on the conceptual development of variational and covariational reasoning. The analyses thus indicate that gestures reflect one's underlying processes in reasoning with the rate of change.

\section{Alignment between Concrete Representations and Symbolic Calculus}

The advanced participants' primary way of representing the volume of water in the bottle (as a series of accumulating disks) aligned very well with the symbolic elements and process of integration. The volume of the water in the bottle may be symbolically represented as the integral of the cross-sectional area over height:

$$
v(h)=\int \pi r^{2} d h
$$

$V$ refers to the volume of water in the bottle; $r$ refers to the radius of the cross-sectional area; $r$ varies linearly with height $h$.

We suggest that the "disk" that participants described as the object of change corresponds to the value of $\pi r^{2}$ (the cross-sectional area) inside the integral. The $\pi r^{2}$ is critical because it describes the rate of change of volume in terms of height (i.e., $\left.v^{\prime}(h)=\pi r^{2}\right)$. Likewise, the very small intervals, often depicted as "thin slices" or by a small gap between two fingers, correspond to the $d h$ of the integral function.

The recursive process of change was often depicted by repeated actions with tiny breaks in between to show consecutive increments, along with a dynamic imagery of a disk expanding with height in a discrete manner. This recursive process aligns well with the concept behind the process of integration, which entails that for every addition of $d h$, there is a new disk to be added to the accumulative volume, and that the volume of that disk is determined by the value of $\pi r^{2}$ at that point of $h$. However, we did not find the same level of alignment between the introductory participants' concrete representations and the integral function. 
Interestingly, we did not explicitly prompt the participants to write an integral function of volume in terms of height; the goal was to find $h(t)$ and h'(t). Nevertheless, the advanced participants spontaneously chose to depict a "disk" and modeled the volume change in the bottle in terms of disk accumulation. Thus, we suggest that the advanced participants might have developed a calculus-based way to conceive dynamic events, which enabled them to model the bottle filling problem in a way which aligned well with the formal symbolic process of integration.

\section{Concrete Representations and Covariational Reasoning}

The differences between the introductory and advanced students can also be examined and explained through the lens of Thompson and Carlson's (2017) research on conceptual levels of covariational reasoning. This analysis provides a convergent way to think of the differences between calculus students of different levels.

By representing the object of change as disks and by representing the process of change as a recursive process, the advanced participant systematically depicted how the changes in one variable (in this case, the volume of a "disk") occurred simultaneously with changes in another variable (height). For example, an advanced participant explained, "for every increase in height, the area increases, so it takes more and more water to fill each height (a series of horizontal cutting actions with the hand gradually moving up)." The "area" and the associated gesture corresponded to a "disk", which indicated their attention to an instantaneous change in volume. The notion of "each height", as well as "every increase in height", showed that they attended to the volume changes occurring within small intervals of height. These terms and gestures revealed how the advanced participant systematically coordinated instantaneous changes in volume with infinitesimal units of height. Thompson (2011) used the term a "recursive image of change" to 
describe how people coordinate the changes of one variable with the changes in another variable in such a manner. This is characterized as an advanced way of thinking about rate of change and is fundamental to understanding how a function, its derivative and its integral are conceptually and quantitatively linked (Carlson et al., 2002; Thompson \& Carlson, 2017).

In contrast, the introductory participants usually depicted the overall shape of the bottle without specifying any intervals or other related variables. In addition, they generally depicted a simple inverse relationship between the volume of the bottle and the rate of change (e.g., "the shape is getting bigger and bigger, so the water increases at a slower rate"), but did not focus on depicting how one variable varies instantaneously with another variable. This pattern is consistent with what Carlson and Thompson (2017) called gross coordination of variables in their regard of levels of development in covariational reasoning.

In summary, the advanced participants highlighted an object of change (the area of a disk) that corresponded to the function $\pi r^{2}$ inside the integral $v(h)=\int \pi r^{2} d h$. In addition, their representations of a recursive process not only matched the symbolic procedures of integrating area over height to find volume, but also revealed their more advanced ways of reasoning with variables that vary simultaneously in relation to each other.

\section{Question 3: How did gestures emerge from the pairs' problem-solving process?}

To further explore the affordances of gestures in communicating and advancing one's ways of thinking about the rate of change, we examined how gestures emerged from the pairs' interactions around their concrete representations. We analyzed those data segments that contained concrete representational strategies using interaction analysis (Jordan \& Henderson, 1995). Interaction analysis is a methodology to analyze how interactions unfold in detail— $—$ how a speaker communicates an idea through speech and gestures, and how it might be taken up by 
another and be further developed as a result of interaction. We employed interaction analysis because it has unique advantages for studying the moment-by-moment construction of ideas, while attending to multimodal interactions between participants.

Using interaction analysis, we closely examined the context in which a new concrete representation was generated and examined whether and how it was taken up. Through the analysis, we found that gestures indeed played a role in facilitating one's idea formation and in sharing it with a partner. Moreover, we found that gestures were often generated in the context of assisting one's partner to understand a new idea, or in the context of building on the other's representation to improve their model of rate of change. Next, we present a few excerpts of interactions followed by our analyses to illustrate these findings.

\section{Gestures Facilitate Idea Formation}

We first show an example of gestures facilitating an introductory participant's emerging understanding. The first excerpt was discussed earlier, in the context of explaining the coding. A pair drew out the $h(t)$ graph directly without explicitly making any representations to explain their reasoning. Then they were asked by the researcher to explain how they arrived at the $h(t)$ graph. The parts of participants' speech and gestures showing an object of change or a process of change were underlined.

\section{Excerpt 1}

Introductory: This one [pointing to the first part of their $\mathrm{h}(\mathrm{t})$ graph], it has [verbal pause while hands making a round funnel shape; see Figure 3 ] a smaller capacity to hold, like a smaller volume.

Advanced: It is constant rate.

Introductory: Right, it is constant. 
Advanced: Like, each slice is the same [hand showing multiple horizontal cutting actions while moving up in a discrete manner; see Figure 4]. And that's why the derivative is like that [pointing to first part of h'(t)].

In this interaction, we saw that the introductory participant produced gestures to communicate their thoughts in the presence of a partner. The participant first produced a gesture representing the shape of the bottle, followed by a pause, before putting it into words- "a smaller capacity" and "a smaller volume". The pause between their gestures and speech indicated that they might not have a well-formed idea about the object of change initially, and might be forming an idea in the moment with the help of their gesture; their gesture seemed to help them come up with words to define the object of change. Consequently, the participant's verbal description shifted from an ambiguous "it" to a more defined "volume" at the end of their turn. In other words, their gestures preceded speech and might have guided the expression of that idea in speech.

\section{Gestures in the Context of Improving Models of Rate of Change}

Excerpt 1 also highlighted the difference between the two participants in how they defined the key variable in reasoning about the rate of change: an advanced participant produced gestures in the context of improving a model initially constructed by the introductory participant. Following the introductory participant, the advanced participant also focused on the object of change - the "disk", which differed from the introductory participant's representation of a “funnel". It was expressed through both speech ("each slice”) and gestures (hand flattened horizontally to show a disk). We suggest that seeing the introductory participant's gesture (a funnel shape), along with hearing their speech, might have prompted the advanced participant to represent an alternative object of change (the disk), which could more effectively model the rate of change. Moreover, producing this gesture also helped to introduce to the introductory 
participant a recursive process of change: while saying "each slice", they moved their hand upward in a discrete matter. Thus, the advanced participant's speech and gestures made explicit a new, calculus-based way of reasoning with the rate of change in this context. In summary, this excerpt demonstrates that an advanced participant produced gestures in the context of improving a rate-of-change model initially constructed by the introductory participant.

We found a similar pattern of interactions across many of the pairs. In 6 out of 10 pairs, the advanced participants produced representational gestures as well as speech in the context of helping to improve their introductory partner's models of rate of change. They often specified the object of change as a "disk" after the introductory participants used terms such as "it" "funnel" or "shape". In addition, the advanced participants specified a recursive process of change, in response to the introductory participant's representation of a continuous process of change. In turn, the introductory participants might adjust their own speech and gestures, based on what their advanced partners modified.

Next, we present two more excerpts to show how the advanced participants generated speech and gestures that embodied more advanced conceptions of rate of change, in the context of modifying the introductory participants' concrete representational models.

In Excerpt 2 from another pair, the advanced participant made a modification to the process of change as well as the object of change that the introductory participant initially constructed.

\section{Excerpt 2}

Introductory: Intuitively, as r increases [pointing to the side of the bottle], it's going to take a larger volume of water to fill up, we don't know it's hard to explain. 
Advanced: So, it takes larger cross-sectional area of water to fill each height [holding a small gap between two fingers to show a small segment of height].

In this excerpt, the advanced participant made two modifications to the representational model made by the introductory participant. First, the advanced participant modified the object of change from "a larger volume of water" to "a larger cross-sectional area". In addition, the advanced participant added a unit "each height" to supplement the "fill up" process described by the introductory participant, which was a modification to the process of change-from continuous to recursive. The advanced participant's modification highlighted the critical object of change - the cross-sectional area (or the disk). Moreover, the addition of "each height" presented a recursive process of change, which was in alignment with the process of integration.

There were 4 incidents where an introductory participant represented a disk with gestures but only 1 such instance in speech, which suggest that gestures might have an advantage over speech for the introductory participants to improve their models of rate of change. In Excerpt 3, we analyze the speech and gestures of a pair who did not depict a "disk" initially but did so eventually through a process of collaboratively making and improving a concrete representational model to explain the rate of change. We saw evidence of an introductory participant modifying their own representation through gestures as the outcome of working with a more advanced partner. This example may help to explain why we found more representations of a "disk" in the introductory participants' gestures than in their speech and why gestures might facilitate learning.

\section{Excerpt 3}

Advanced: Height goes faster here [pointing to the cylindrical part of the bottle] and then gets slower and slower. So, it gets less and less steep. 
Researcher: Why is it less and less steep?

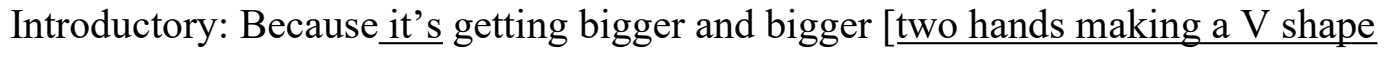
gesture], so the rate at which the thing is filling up slows down (pause). It's going at constant rate until it slows down; at a constant rate; not curved.

Advanced: Yes.

Researcher: Why does it decrease linearly?

Introductory: Because there is no change at the rate [pointing to the $\alpha \mathrm{ml} / \mathrm{s}$ on the board, which refers to the rate of water being added].

Advanced: Because the ratio is constant.

Researcher: OK. Can you tell me again what gets bigger and bigger when water fills up? Advanced: The radius increases [drawing a circle in the air]. Introductory: The radius [thumbs and index fingers making a circle that is expanding and rising up simultaneously].

Researcher: And you think the rate slows down because?

Advanced: Since you are filling up something that is getting bigger, it takes longer to fill the whole area [flattened hands showing the water surface].

This is a very interesting excerpt because both the advanced participant and the introductory participant modified their concrete representational models in the process of collaboratively explaining about the rate of change. They did so through both gestures and speech.

In terms of gestures, both participants' gestures were affected by what their partner did. On the one hand, the advanced participant, who did not gesture initially, introduced two gestures (a circle and a flat hand) to represent a disk after seeing the V-shape gesture by the introductory participant. On the other hand, the introductory participant modified his gesture from a V-shape 
gesture to a disk gesture after the advanced participant introduced a disk by drawing a circle in the air. Thus, both participants modified and advanced their ways of representing rate of change through their gestures, as a result of this interaction.

In terms of speech, both the introductory participant and the advanced participant modified their verbal reference to the object of change from "it" to "radius", in the process of improving their model of rate of change. Although "radius" was more defined than "it", it did not reflect an image of a "disk". At the end of this excerpt, however, the advanced participant eventually modified the term "radius" to "area" (an alternative term to describe an image of a disk in words). Nevertheless, both participants already depicted an image of a disk with their gestures when they were still using the term "radius".

In summary, the advanced participants produced representational speech and gestures that embodied their more advanced and calculus-based ways of reasoning with the rate of change, in the context of improving the concrete representational models made by their introductory level partners. In addition, we found that the introductory participants used gestures not only to communicate their ideas but also to facilitate the process of forming a concrete representational model for explaining the rate of change. Moreover, in some situations, they were able to improve their representational gestures through interacting with a more advanced partner.

\section{Discussion}

In this study, we drew on the embodied cognition perspective to examine undergraduate students' underlying conceptions of the rate of change, by exploring their gestures and speech produced in the process of working with a partner to model the rate of change in an everyday context. We paired introductory level undergraduate students with more advanced partners to graph the rate of change of water level rising in a bottle which was being filled. 
We found that the richest and most meaningful interactions between introductory and advanced participants involved concrete representational strategies — either describing in words or demonstrating in gestures embodied concepts related to the rate of change. Both the introductory and advanced participants actively embodied rate of change through their speech and gestures. We identified characteristics of speech and gestures that distinguished the advanced participants' concrete representations from those of the introductory participants. Our analyses of the representational differences between the two groups of participants shed light on some important features of gestures, which might reflect and facilitate complex and advanced ways of reasoning about the rate of change. Specifically, the advanced participants primarily produced (in speech, gesture, or both) a "disk" shaped object and a recursive process of change. These speech and gestures embodied advanced types of variational reasoning and covariational reasoning, which are critical to learning the rate of change (Carlson, et al., 2002; Thompson \& Carlson, 2017). Put simply, these representational speech and gestures demonstrate that learning calculus influenced how participants conceived the object of change and the process of change.

In addition, our analysis of the interactions between the pairs indicate that gestures might facilitate learning the rate of change - gestures were produced in the context of explaining to another or improving a representational model. Next, we highlight some features of gestures and discuss how those features might afford learning and reasoning about the rate of change.

\section{Dynamic Gestures: Continuous vs. Recursive}

Marghetis and Núñez (2013) indicate that dynamic gestures may reveal learners’ dynamic conceptions of calculus, such as the concept of "increasing" function and the concept of continuity. In our study, both groups of participants used dynamic gestures, which reflected their dynamic conceptions of rate of change. This makes sense because all participants, including the 
introductory participants, already had some exposure to calculus before this study - they had either completed a college level calculus course or had taken a calculus course in high school and were taking a college level calculus course at the time of this study. Nevertheless, there were differences between the introductory and more advanced participants in the kinds of dynamic gestures they used.

We classified the participants' dynamic gestures into two categories: continuous and recursive. The advanced participants primarily used recursive gestures - gestures that demonstrate a repeated pattern — whereas the introductory participants often used continuous gestures to represent the overall trend in which the water level and the volume inside the bottle increased with height. This distinction was very interesting because it might initially seem contradictory to the conceptual advancement from a "chunk image of change" to a "smooth and continuous image of change" (Castillo-Garsow, 2012; Castillo-Garsow, Johnson, \& Moore, 2013) concerning how learners conceive change within a variable. Given the conceptual development, one should expect that the more advanced participants would be more likely to use continuous gestures which reflect a "smooth and continuous image of change". However, we found that the continuous gesture was the primary type of gesture by the introductory participants. Although we found 3 out the 10 advanced participants who used this type of gesture (but two of them also used recursive gestures), it was not the primary type of gesture used by the advanced participants. Why?

The recursive gesture, primarily used by the advanced participants, seemed to signify a "recursive" image of change (Thompson, 2011), which reflects an advanced way of coordinating the relation between co-varying variables. As we have demonstrated in addressing Question 2, the advanced participants used words like "each height", and accompanying gestures to 
demonstrate how the disks expanded with every increase in height; they chose recursive gestures to model a discrete, step-by-step process of change, in order to relate the instantaneous change in the area of the disks with an infinitesimal change in height.

We think that the advanced participants might have intentionally chosen the "recursive image" over the "smooth and continuous image" to signify the co-varying relation between two variables (area of the disk and height), instead of signifying the continuous change within one variable. There were obvious advantages of signifying the co-varying relation between variables in solving this problem: because the problem asked participants to find the rate of change of height with respect to time and because the amount of water being added per second is constant, reasoning about the relation between the change in the amount (volume) of water and the change in height is key to solving the problem.

Thus, we suggest that the more advanced participants might have developed expertise in selecting the most effective representation to model the rate of change, which is reflected in their use of gestures. The recursive gestures primarily used by advanced participants have special affordances in coordinating the change in one variable with the change in co-varying variables and thus facilitate reasoning about the rate of change. These gestures display features that are like dynamic depictive gestures produced for making geometric proofs (Walkington et al., 2014). In their study, the participants used dynamic gestures to transform part of an object to test impact on the rest of the object. In our study, the advanced participants used dynamic gestures to represent an instantaneous change in a variable and related the change fluidly with continuous change in another variable. In both cases the dynamic gestures showed advantages in facilitating some exploration of dynamic changes and relations. 


\section{The Interaction between Speech and Gestures}

The study examined representational speech and gestures both independently and in relation. We found that the frequency distributions of objects ("radius", "disk" and "funnel") and processes (static, continuous, and recursive) in speech were not exactly the same as those in gestures, for both advanced and beginning students. This finding suggested that there were times when the participants conveyed different ideas or different aspects of rate of change in speech and gestures. For example, a participant might demonstrate a recursive process of change by gesturing intervals with a series of repeated actions while saying, "it keeps increasing", without describing the interval or the dynamic process in words.

Gestures have been shown to be an early indicator of learning and support the formation of the same idea in words (e.g., Alibali \& Goldin-Meadow, 1993; Church \& Goldin-Meadow, 1986; Goldin-Meadow, Alibali, \& Church, 1993). In our study, we suggest that gestures might have helped some introductory participants form and communicate their models of rate of change. For example, in Excerpt 1, gesturing the shape of a bottle in the context of explaining to another person promoted an introductory participant to come up with a verbal referent ("volume") to the object of change, which made an otherwise ambiguous or tacit conceptual entity definite. The introductory participant's gestures might have facilitated their thinking and communication because these representational gestures highlighted the perceptually present information (e.g., the shape of an object) for the speaker (Alibali \& Kita, 2010) when communicating their models of the rate of change. Similarly, in Excerpt 3, the introductory participant was able to modify their object of change to a "disk" through gestures while still using the term "radius". Thus, we suggest that in some situations, it might be easier to begin the 
process of communicating or modifying a concrete representational model with gestures, rather than with speech.

\section{Gestures in Collaborative Problem-solving}

We found that the participants produced a high concentration of representations (in speech, gestures, or both) around their different ways of seeing and reasoning about the rate of change in this collaborative problem-solving setting. Different representations emerged mainly in forms of modifications offered by an advanced participant, following an initial representation made by the introductory-level partner. In addition, we found that modification offered in gestures were more frequent than in speech. Prior research (Gerwing \& Bavelas, 2004; Holler \& Stevens, 2007; McNeil, 2005) sheds light on possible causes of this difference: speakers are likely to gesture about information that is particularly noteworthy, such as information that contrasts information already present. Thus, an obvious advantage of gesturing in this collaborative setting was that it highlighted how the pair of participants viewed rate of change differently and thus created opportunities for the advanced participant to offer immediate modifications to introductory participant's model.

Gestures also played an important role in collaboratively improving the models of rate of change. In cases where advanced participants gestured frequently, the introductory participants were also more likely to gesture and modify their gestures. For example, in Excerpt 3, we saw evidence of an introductory participant modifying their own representation through gestures as the outcome of working with a more advanced partner. It is likely that gesturing is the more accessible means of representation for introductory participants to engage with. This perspective may help us understand why the introductory participants made more advanced types of representations through gestures than speech. 
Moreover, as gestures may play a unique role in influencing how mathematical ideas are understood through simulation of actions and perceptions (Alibali \& Nathan, 2012; GoldinMeadow \& Beilock, 2010), we may positively infer that introductory level participants will likely benefit from seeing their more advanced partners' gesture modifications and adjusting their own gestures. However, the current study only focused on changes in external representations during problem solving and did not measure such conceptual change in-depth. Moreover, since this is a collaborative task, an introductory participant may find it unnecessary to reiterate a modification already made by the partner. Therefore, the introductory participants' modification of representations might not be a comprehensive measure of their learning gain. In future studies, follow up interviews or post-tests will be needed to understand how such modification influence the coordination of embodied and formal knowledge.

\section{Embodied Knowledge and Formalism}

We mainly focused on uncovering the different kinds of embodied knowledge among calculus students through studying their speech and gestures that were produced to model a concrete dynamic phenomenon. Nevertheless, we did find that the group of advanced participants, who mainly represented disk-liked objects and recursive processes of change, also used more equational strategies than their less advanced partners. This finding indicates that the advanced participants' preferences for those types of representations might be correlated with their abilities to construct formal calculus functions to model the rate of change. Moreover, as shown in our analysis, the advanced participants' concrete representations align well with formal symbolic calculus. We therefore suggest that their ways of perceiving dynamic events in terms of infinitesimal units of change in relation to the incremental changes of another variable might have assisted them to formulate calculus functions to solve this real-world problem. For instance, 
the advanced participants' concrete representations could guide them to define the surface area of the bottle as $\pi r^{2}$ and the incremental changes in height as $d h$, which are essential elements in the calculus equation. This claim resonates with Tall's (2004) idea that embodied knowledge may further develop through learning symbolic procedures and facilitate the development of more sophisticated formal ideas.

\section{Conclusion}

Both introductory and advanced students applied their embodied knowledge to solve the rate of change problem. But there was also a fundamentally important difference between the introductory and advanced students: The embodied representations of the more advanced students were influenced by their knowledge of integrals (a fundamental calculus concept); their representations often signified an infinitesimal change in the independent variable and its effect on the dependent variable. In contrast, the embodied representations of the introductory participants often highlighted an overall continuous trend. These differences were consistent with research (Thompson \& Carlson, 2017) on levels of conceptual development in covariational reasoning, which concerns how learners conceive change within one variable and how they coordinate changes in one variable with another. Our study thus suggests that learning calculus might affect how learners conceive rate of change in everyday contexts and how they coordinate dynamic relations of multiple variables.

Our analyses of concrete representational strategies also show that gestures might facilitate reasoning about the rate of change in several ways. First, dynamic depictive gestures (Walkington et al., 2014), including the recursive gestures frequently used by advanced participants, could assist coordinating the relationship between covarying variables, which is crucial for reasoning about the rate of change. Second, gestures assisted the introductory 
participants to form and communicate their ideas about rate of change. In addition, the advanced participants frequently produced gestures that highlighted a new way of conceiving the rate of change that differed from what the introductory participants often conceived. Because sharing these gestures might encourage the introductory participants to conceive rate of change in a new way (Alibali \& Nathan, 2012; Goldin-Meadow \& Beilock, 2010), these gestures produced in the collaborative problem-solving setting might facilitate learning the rate of change.

In summary, analysis of gestures and speech allowed us to move beyond a simple description of mathematical knowledge as "embodied" or "concrete" and to investigate how everyday conceptions of rate of change evolve as a result of studying calculus. Although all students demonstrated embodied representations, the content of these representations differed as a function of what they learned by studying calculus. Teachers might find it valuable to examine students' gestures (and speech) to investigate whether instruction has affected students' knowledge. 


\section{Acknowledgments}

This research was supported by the NSF-funded Spatial Intelligence and Learning Center, Award \#SBE-1041707.

We would like to thank the undergraduate students and research assistants in our lab for helping with data analysis, providing feedback, and assisting with figure production. 


\section{References}

Alibali, M. W., \& Goldin-Meadow, S. (1993). Gesture-speech mismatch and mechanisms of learning: what the hands reveal about a child's state of mind. Cognitive psychology, 25(4), 468-523. doi: 10.1006/cogp.1993.1012

Alibali, M. W. \& Hostetter, A. B. (2010). Mimicry and simulation in gesture comprehension (Commentary on P. Niedenthal, M. Maringer, M. Mermillod, \& U. Hess, The Simulation of Smiles (SIMS) model: Embodied simulation and the meaning of facial expression). Behavioral and Brain Sciences, 33, 433-434.

Alibali, M. W. \& Kita, S. (2010). Gesture highlights perceptually present information for speakers. Gesture, 10(1), 3-28. doi: 10.1075/gest.10.1.02ali

Alibali, M.W., \& Nathan, M (2012). Embodiment in Mathematics Teaching and Learning: Evidence from Learners' and Teachers' Gestures. Journal of the Learning Sciences, 21(2), 247-286. doi: 10.1080/10508406.2011.611446

Ärlebäck, J. B., Doerr, H. M., \& O'Neil A. H. (2013). A Modeling Perspective on Interpreting Rates of Change in Context. Mathematical Thinking and Learning, 15(4), 314-336. doi: $10.1080 / 10986065.2013 .834405$

Bell, A., \& Janvier, C. (1981). The Interpretation of Graphs Representing Situations. For the Learning of Mathematics, 2(1), 34-42.

Bjuland, R., Cestari, M., L.\& Borgersen, H., E. (2008) The Interplay Between Gesture and Discourse as Mediating Devices in Collaborative Mathematical Reasoning: A Multimodal Approach. Mathematical Thinking and Learning, 10(3), 271-292. doi: $10.1080 / 10986060802216169$ 
Broaders, S. C., Cook, S. W., Mitchell, Z., \& Goldin-Meadow, S. (2007). Making children gesture brings out implicit knowledge and leads to learning. Journal of Experimental Psychology: General, 136(4), 539-550. doi: 10.1037/0096-3445.136.4.539

Bruner, J. S. (1966). Toward a theory of instruction. Cambridge: Harvard University Press.

Carlson, M., Jacobs, S., Coe, E., Larsen, S., \& Hsu, E. (2002). Applying covariational reasoning while modeling dynamic events: A framework and a study. Journal for Research in Mathematics Education, 33(5), 352-378. doi: 10.2307/4149958

Castillo-Garsow, C. (2012). Continuous quantitative reasoning. In R. Mayes \& L. L. Hatfield (Eds.), Quantitative reasoning and mathematical modeling: A driver for STEM integrated education and teaching in context (Vol. 2, pp. 55-73). Laramie, WY: University of Wyoming College of Education.

Castillo-Garsow, C., Johnson, H. L., \& Moore, K. C. (2013). Chunky and smooth images of change. For the Learning of Mathematics, 33(3), 31-37.

Chafe, W. L. (1979). The flow of thought and the flow of language. In T. Givon (Ed.), Syntax and semantics, vol. 12: Discourse and syntax (pp. 159-181). New York: Academic Press.

Chafe, W. L. (1980). The development of consciousness in the production of a narrative. In W. L. Chafe (Ed.), The pear stories: Cognitive, cultural, and linguistic aspects of narrative production (pp. 9-50). Norwood, NJ: Ablex.

Church, R. B., \& Goldin-Meadow, S. (1986). The mismatch between gesture and speech as an index of transitional knowledge. Cognition, 23, 43-71. doi: 10.1016/0010-0277(86)900533 
Cook, S. W., \& Goldin-Meadow, S. (2006). The Role of Gesture in Learning: Do Children Use Their Hands to Change Their Minds? Journal of Cognition and Development, 7(2), 211232. doi: $10.1207 / \mathrm{s} 15327647 \mathrm{jcd} 0702 \_4$

Cook, S. W. \& Tanenhaus, M. (2009). Embodied understanding: Speakers' gestures affect listeners' actions. Cognition, 113, 98-104. doi: 10.1016/j.cognition.2009.06.006

Edwards, L. D. (2009). Gestures and conceptual integration in mathematical talk. Educational Studies in Mathematics, 70, 127-141. doi: 10.1007/s10649-008-9124-6

Gerwing, J. \& Bavelas, J. (2004). Linguistic Influences on Gesture's Form. Gesture, 4, 157-195. doi: 10.1075/gest.4.2.04ger

Goldin-Meadow, S., Alibali, M. W., \& Church, R. B. (1993). Transitions in concept acquisition: Using the hand to read the mind. Psychological Review, 100, 279-297. doi: 10.1037/0033295X.100.2.279

Goldin-Meadow, S., \& Beilock, S. L. (2010). Action's influence on thought: The case of gesture. Perspectives on Psychological Science: a journal of the Association for Psychological Science, 5(6), 664-674. doi:10.1177/1745691610388764

Goldin-Meadow, S., Cook, S.W., Mitchell, Z. A. (2009). Gesturing gives children new ideas about math. Psychological. Science. 20(3), 267-272. doi: 10.1111/j.1467-9280.2009.02297.x

Gray, E. M., \& Tall, D. O. (2001). Relationships between embodied objects and symbolic procepts: An explanatory theory of success and failure in mathematics. In M. van den Heuvel-Panhuizen (Ed.), Proceedings of 25th annual conference of the International Group for the Psychology of Mathematics Education (Vol. 3, pp. 65-72). Utrecht, The Netherlands: PME. 
Holler, J., \& Stevens, R. (2007). The Effect of Common Ground on how Speakers use Gesture and Speech to Represent Size Information. Journal of Language and Social Psychology, 26(1), 4-27. doi: 10.1177/0261927X06296428

Hostetter, A. B., \& Alibali, M. (2008). Visible embodiment: Gestures as simulated action. Psychonomic Bulletin \& Review, 15, 495-514. doi: 10.3758/PBR.15.3.495

Kim, M., Roth, W. M., \& Thom, J. (2011). Children's gestures and the embodied knowledge of geometry. International Journal of Science and Mathematics Education, 9(1), 207-238

Lakoff, G., \& Núñez, R. (2000). Where mathematics comes from: How the embodied mind brings mathematics into being. New York: Basic Books.

Marghetis, T., \& Núñez, R. (2013). The Motion Behind the Symbols: A Vital Role for Dynamism in the Conceptualization of Limits and Continuity in Expert Mathematics. Topics in Cognitive Science, 5(2), 299-316. doi:10.1111/tops.12013

McNeill, D. (2005). Gesture and thought. Chicago, IL, US: University of Chicago Press. doi:10.7208/chicago/9780226514642.001.0001

Nemirovsky, R., Kelton, M. L., \& Rhodehamel, B. (2013). Playing Mathematical Instruments: Emerging Perceptuomotor Integration with an Interactive Mathematics Exhibit. Journal for Research in Mathematics Education, 44(2), 372-415. doi:10.5951/jresematheduc. 44.2 .0372

Piaget J. (1977) The Role of Action in the Development of Thinking. In: Overton W.F., Gallagher J.M. (Eds), Knowledge and Development (pp. 17-42). Springer, Boston, MA. doi: 10.1007/978-1-4684-2547-5_2 
Radford, L. (2009). Why do gestures matter? Sensuous cognition and the palpability of mathematical meanings. Educational Studies in Mathematics, 70(2), 111-126. doi: $10.1007 /$ s10649-008-9127-3

Radford, L. (2014). Towards an embodied, cultural, and material conception of mathematics cognition. ZDM Mathematics Education, 46(3), 349-361. doi: 10.1007/s11858-014-05911

Reynolds, F., \& Reeve, R. (2002). Gesture in collaborative mathematics problem solving. Journal of Mathematical Behavior, 20, 447-460. doi:10.1016/S0732-3123(02)00091-3

Tall, D. O. (2004). The three worlds of mathematics. For the Learning of Mathematics, 23(3), 2933.

Thompson, P. W. (2011). Quantitative reasoning and mathematical modeling. In L. L. Hatfield, S. Chamberlain, \& S. Belbase (Eds.), New perspectives and directions for collaborative research in mathematics education, WISDOMe Monographs (Vol. 1, pp. 33-57). Laramie: University of Wyoming.

Thompson, P. W., \& Carlson, M. P. (2017). Variation, covariation and functions: Foundational ways of mathematical thinking. In J. Cai (Ed.), Compendium for research in mathematics education (pp. 421-456). Reston, VA: National Council of Teachers of Mathematics.

Walkington, C., Boncoddo, R., Williams, C., Nathan, M., Alibali, M., Simon, E., et al. (2014). Being mathematical relations: dynamic gestures support mathematical reasoning. In W. Penuel, S. A. Jurow, \& K. O’Connor (Eds.), Learning and becoming in practice: Proceedings of the Eleventh International Conference of the Learning Sciences (pp. 479486). Boulder, CO: University of Colorado. doi: 10.13140/2.1.4080.0005 
Wilkerson-Jerde, M. \& Wilensky, U. (2011). How do mathematicians learn math?: Resources and acts for constructing and understanding mathematics. Educational Studies in Mathematics, 78(1), 21-43. doi: 10.1007/s10649-011-9306-5

Yoon, C., Thomas, M. O. J., \& Dreyfus, T. (2011). Gestures and insight in advanced mathematical thinking. International Journal of Mathematical Education in Science and Technology, 42(7), 891-901. doi: 10.1080/0020739X.2011.608861 


\section{Appendix}

\section{Structure of Codes for Concrete Representational Strategies}

- Gestures

- Representational: (representing concrete elements of the funnel problem)

- Object of change:

- "Disk": drawing a circle in the air; a cut or cuts; or flatten a hand horizontally

- Funnel: V-shape, round-shape gesture representing the cone

- Radius: drawing or pointing to a line that represents the width/side of the container

- Process of change:

- Dynamic

○ Recursive: discrete, step-by-step movements; e.g. taking multiple horizontal cuts while raising hand.

- Note: whenever a person says "each slice" or something similar that shows a step-by-step process, code as Recursive.

○ Continuous: smooth

- Static

- Fixed gestures showing no process of change.

o Other: e.g. Pointing to the bottle diagram.

- Speech

- Representational: (representing concrete elements of the funnel problem)

- Object of change:

- "Disk/slice": one specific disk imagery. e.g. "slice, disk, area, cross-section, etc."

- "Radius": Linear side: e.g. "the side / width, is straight up and down..."

- "Funnel": e.g. "space, opening, container, funnel, cylinder/cone, etc."

- Process of change:

- Dynamic

○ Recursive: involves changes by unit, e.g. "for every inch up here, it's going to take longer because it's wider." Note: look for key words: "each", "every"

- Static

○ Continuous: e.g. "it gets bigger and bigger"

o e.g. There's more space (when comparing the cone with the cylinder part of the funnel) 


\section{Table 1}

Three Categories of Strategies

Category Examples (Speech, with gestures and drawings described)

Concrete A: "The rate of change of water is constant. But the rate of change of

Representational volume is increasing, so there's less of a height increase as it goes up [a horizontal flat hand moving up]."

Graphical A: "The height increases linearly here [pointing to the linear section of the graph $h(t)$ ], so the rate of change is constant here [drawing a horizontal line segment on the $h^{\prime}(t)$ graph]."

A: "This one [pointing to the $h$ ' $(\mathrm{t})$ graph in Figure $2 \mathrm{c}$ ] means that the rate of change keeps decreasing and goes below zero, but the rate should never become negative because it (the height) is increasing."

Equational A: "What's the volume of a cone?"

B: "Hmm... It's one-third the area of the base times the height. Do we know the area?"

A: "So the area is $\pi r^{2}$ and height is $h$ [writing $\mathrm{V}=\pi r^{2} h$ on the board]. Are we supposed to take the derivative?"

A: "We know that the rate has to do with the area...is it suggesting a quadratic relationship? Something squared?"

Note. A and B refer to two partners in each strategy example. Gestures are described with text in brackets. 


\section{Table 2}

Three Categories of the Object of Change

\begin{tabular}{|c|c|c|c|}
\hline Туре & Definition & $\begin{array}{l}\text { Examples } \\
\text { in speech }\end{array}$ & Examples in gesture \\
\hline Radius & $\begin{array}{l}\text { A } 1 D \\
\text { representation } \\
\text { of width } \\
\text { /radius of the } \\
\text { container. }\end{array}$ & $\begin{array}{l}\text { "width" } \\
\text { "radius" } \\
\text { "side" }\end{array}$ & $\begin{array}{l}\text { Highlighting with fingers the width or side of the } \\
\text { container on the diagram }\end{array}$ \\
\hline Disk & $\begin{array}{l}\text { A } 2 \mathrm{D} \\
\text { horizontal } \\
\text { circle or a thin } \\
\text { 3D horizontal } \\
\text { disk, } \\
\text { representing } \\
\text { the surface } \\
\text { area of water } \\
\text { in the bottle. }\end{array}$ & $\begin{array}{l}\text { "slice" } \\
\text { "disk" } \\
\text { "area" } \\
\text { "cross- } \\
\text { section" }\end{array}$ & $\begin{array}{l}\text { Making a circle with both hands; a cutting action; } \\
\text { holding a small gap between two fingers to show a } \\
\text { small segment of height }\end{array}$ \\
\hline Funnel & $\begin{array}{l}\text { A } 2 \mathrm{D} \text { or } 3 \mathrm{D} \\
\text { representation } \\
\text { of the overall } \\
\text { shape of the } \\
\text { container, } \\
\text { could be two } \\
\text { parts: a } \\
\text { cylinder and a } \\
\text { cone }\end{array}$ & $\begin{array}{l}\text { "room" } \\
\text { "space" } \\
\text { "funnel" } \\
\text { "cylinder" } \\
\text { "cone" }\end{array}$ & Making a V-shape or a round shape with both hands \\
\hline
\end{tabular}

Note. Images are demonstrations produced by the researchers for greater clarity. 


\section{Table 3}

Three Categories of Processes of Change

\begin{tabular}{|c|c|c|c|}
\hline Type & Definition & Examples in speech & Examples in gesture \\
\hline Static & $\begin{array}{l}\text { A still shape, } \\
\text { showing no } \\
\text { change nor } \\
\text { continuity; } \\
\text { often for } \\
\text { comparing the } \\
\text { cylindrical } \\
\text { part with the } \\
\text { cone part }\end{array}$ & $\begin{array}{l}\text { "This part (cylinder) is } \\
\text { faster because it's } \\
\text { smaller, so there's less } \\
\text { space." } \\
\text { "This part (cone) is } \\
\text { wider so it takes more } \\
\text { water to spread out." }\end{array}$ & $\begin{array}{l}\text { Holding a fixed gesture, without } \\
\text { movement }\end{array}$ \\
\hline Continuous & $\begin{array}{l}\text { Showing an } \\
\text { overall } \\
\text { continuous } \\
\text { trend, without } \\
\text { specifying } \\
\text { intervals }\end{array}$ & $\begin{array}{l}\text { "As the height gets } \\
\text { higher and higher, the } \\
\text { area gets bigger and } \\
\text { bigger." } \\
\text { "Because the radius is } \\
\text { increasing, it takes more } \\
\text { time to fill." }\end{array}$ & $\begin{array}{l}\text { A smooth hand movement, showing } \\
\text { a continuous change }\end{array}$ \\
\hline Recursive & $\begin{array}{l}\text { Change in } \\
\text { consecutive } \\
\text { increments, } \\
\text { with small } \\
\text { intervals } \\
\text { specified }\end{array}$ & $\begin{array}{l}\text { "As height increases, it } \\
\text { takes more and more } \\
\text { water to fill each } \\
\text { height." } \\
\text { "For every increase in } \\
\text { height, the area gets } \\
\text { bigger." }\end{array}$ & $\begin{array}{l}\text { Repeated actions with tiny breaks in } \\
\text { between, to show change in } \\
\text { consecutive increments }\end{array}$ \\
\hline
\end{tabular}

Note. Images are demonstrations produced by the researchers for greater clarity. 


\section{Table 4}

Summary of Speech and Gestures Representing an Object of Change

\begin{tabular}{cccccc}
\hline Representation & Participant & \multicolumn{3}{c}{ Object of Change } & Total \\
\cline { 3 - 5 } & & Radius & Disk & Funnel & \\
\hline \multirow{2}{*}{ Speech } & Introductory & 3 & 1 & 8 & 12 \\
& Advanced & 4 & 17 & 1 & 22 \\
Gesture & Introductory & 2 & 4 & 7 & 13 \\
& Advanced & 2 & 18 & 2 & 22 \\
\hline
\end{tabular}




\section{Table 5}

Summary of the Occurrences of Speech and Gestures representing the Process of Change

\begin{tabular}{cccccc}
\hline Representation & Participant & \multicolumn{3}{c}{ Process of Change } & Total \\
\cline { 3 - 5 } & & Static & Continuous & Recursive & \\
\hline \multirow{2}{*}{ Speech } & Introductory & 3 & 7 & 2 & 12 \\
& Advanced & 1 & 3 & 18 & 22 \\
Gesture & Introductory & 2 & 8 & 3 & 13 \\
& Advanced & 1 & 5 & 16 & 22 \\
\hline
\end{tabular}




\section{Figure 1}

Diagram of the Problem

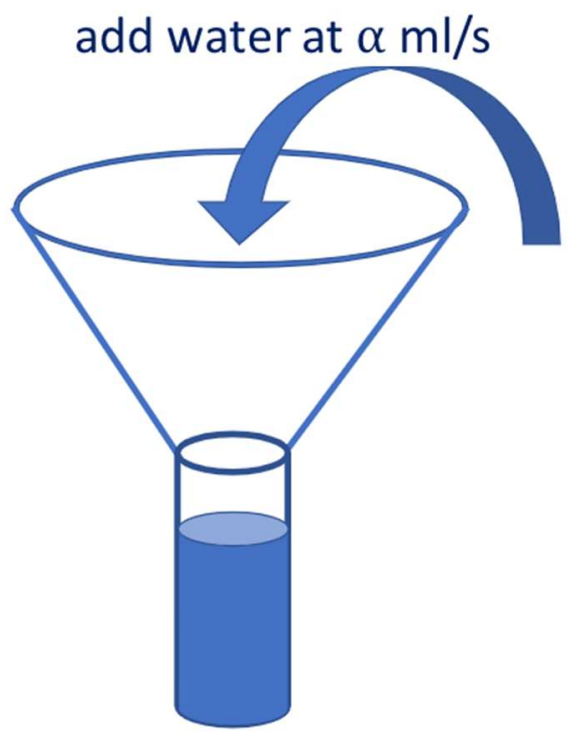




\section{Figure 2}

Three Possible Graphs of the Rate of Change

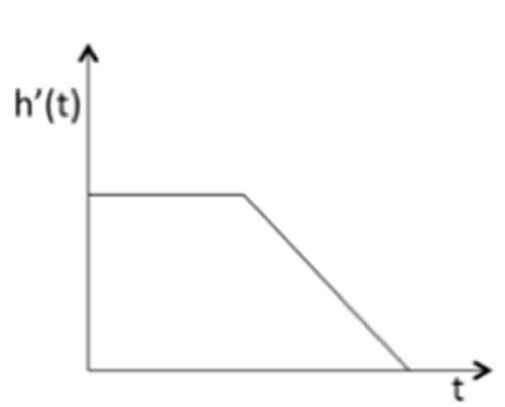

A

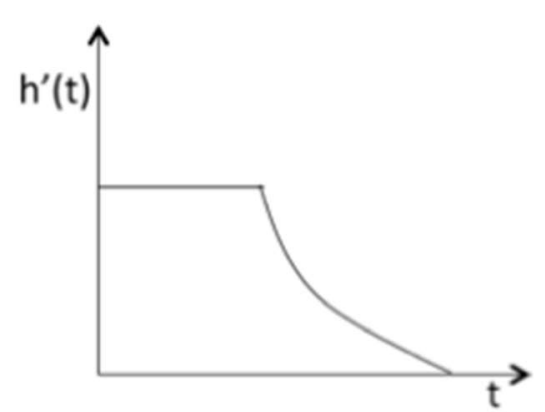

B

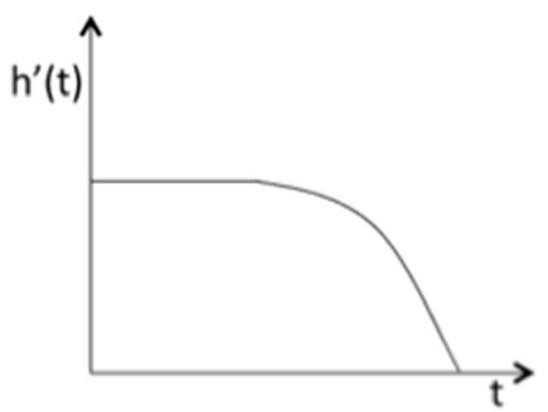

$\mathrm{C}$

Note. These three graphs were based on a pilot study that revealed the most typical h'(t) graphs undergraduates produced to address this problem. All three graphs describe a decreasing trend in the rate of change. Figure $2 \mathrm{~b}$ most closely represented the actual trend of the rate of change. 


\section{Figure 3}

An Introductory Participant's Gesture

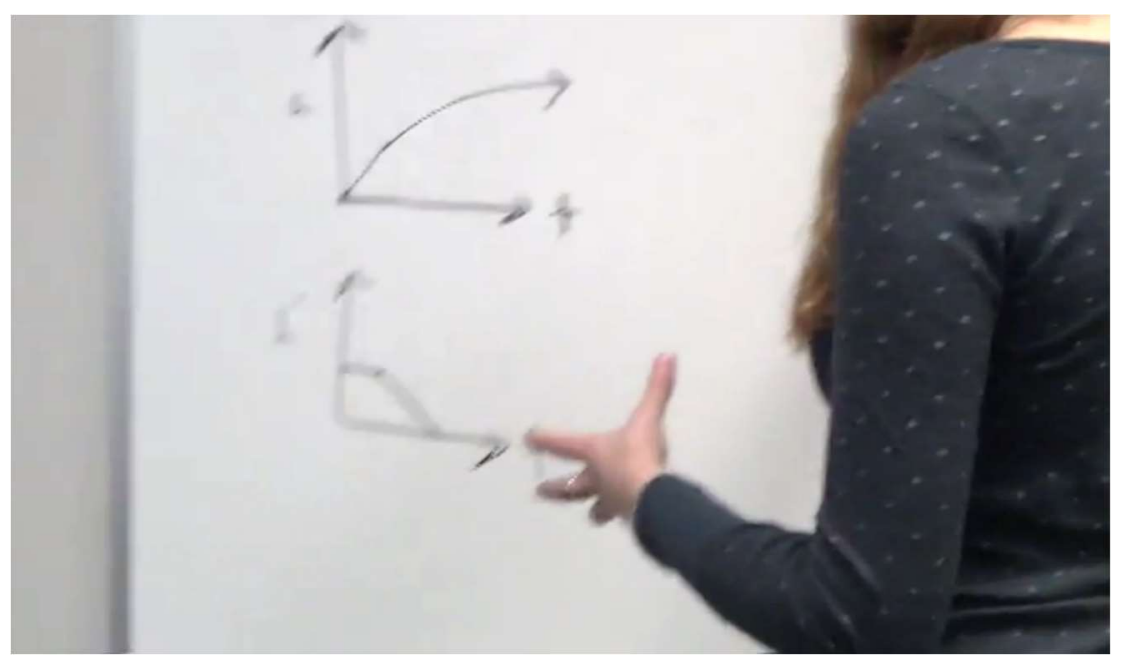




\section{Figure 4}

An Advanced Participant's Gesture

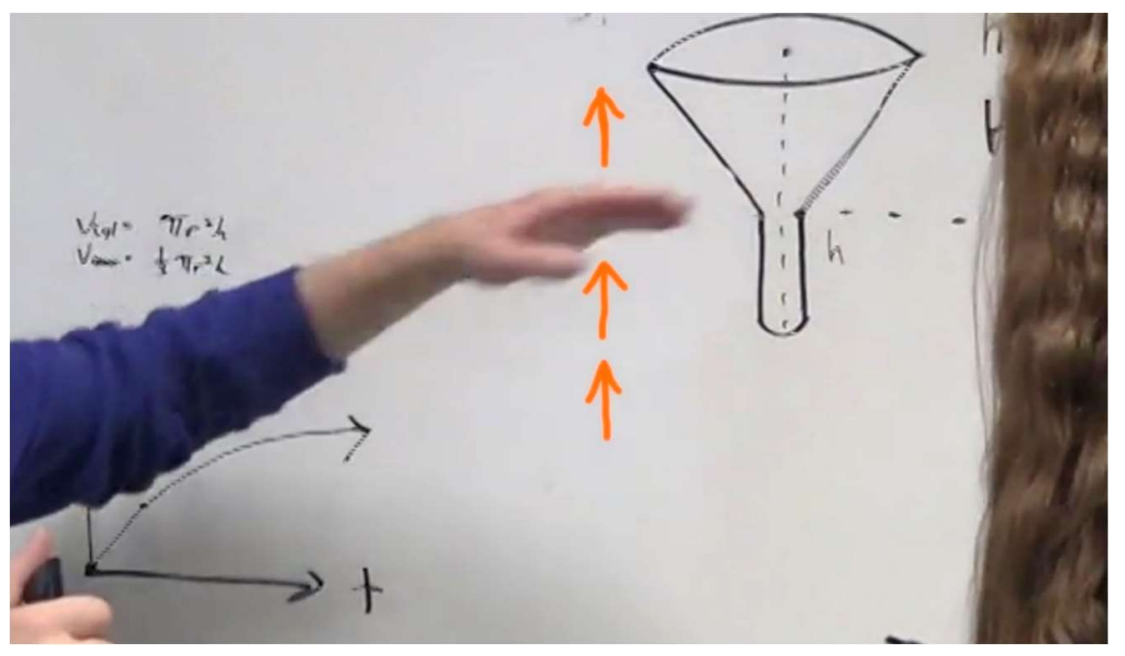




\section{Figure 5}

The Average Proportions of Speech in Three Categories of Objects of Change

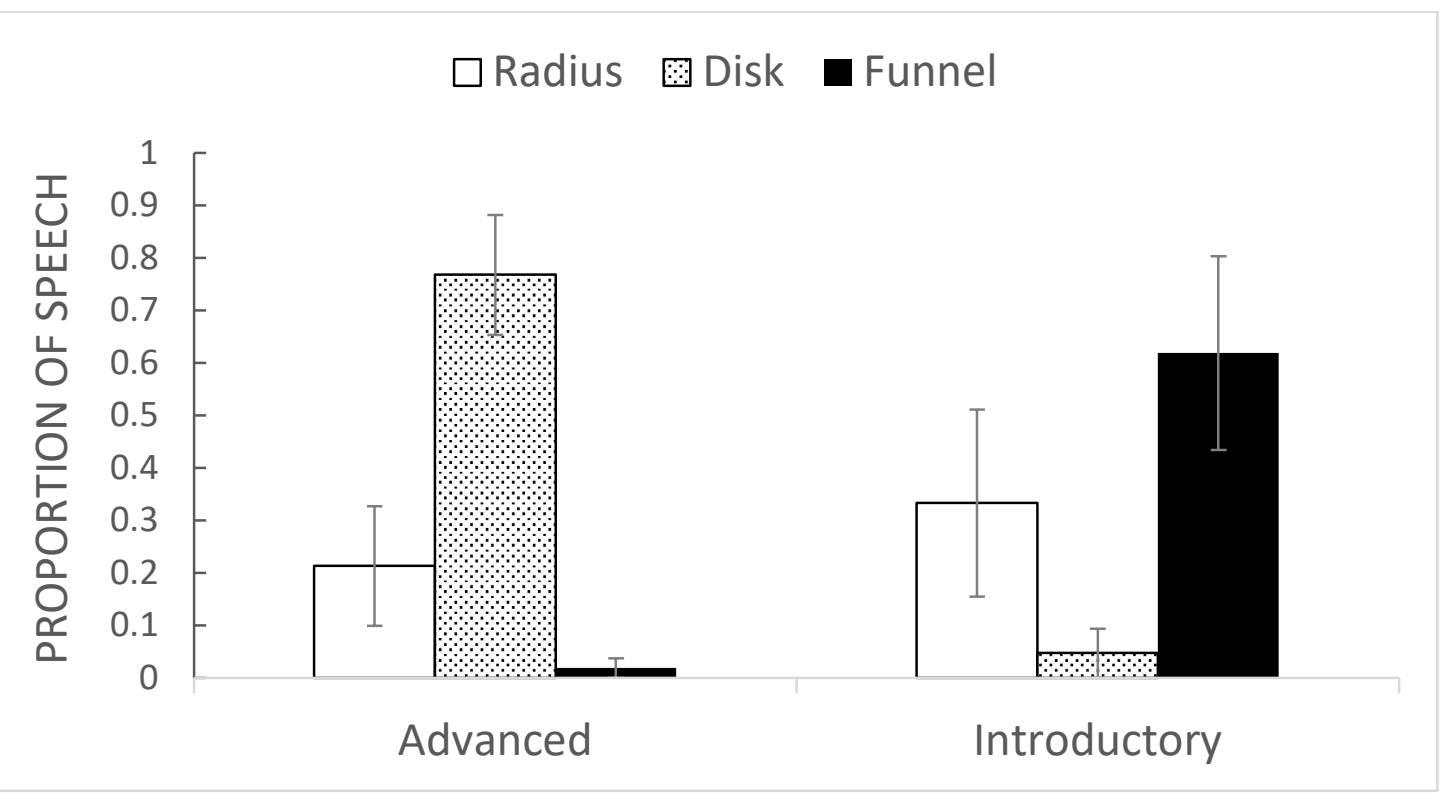




\section{Figure 6}

The Average Proportions of Gestures in Three Categories of Objects of Change

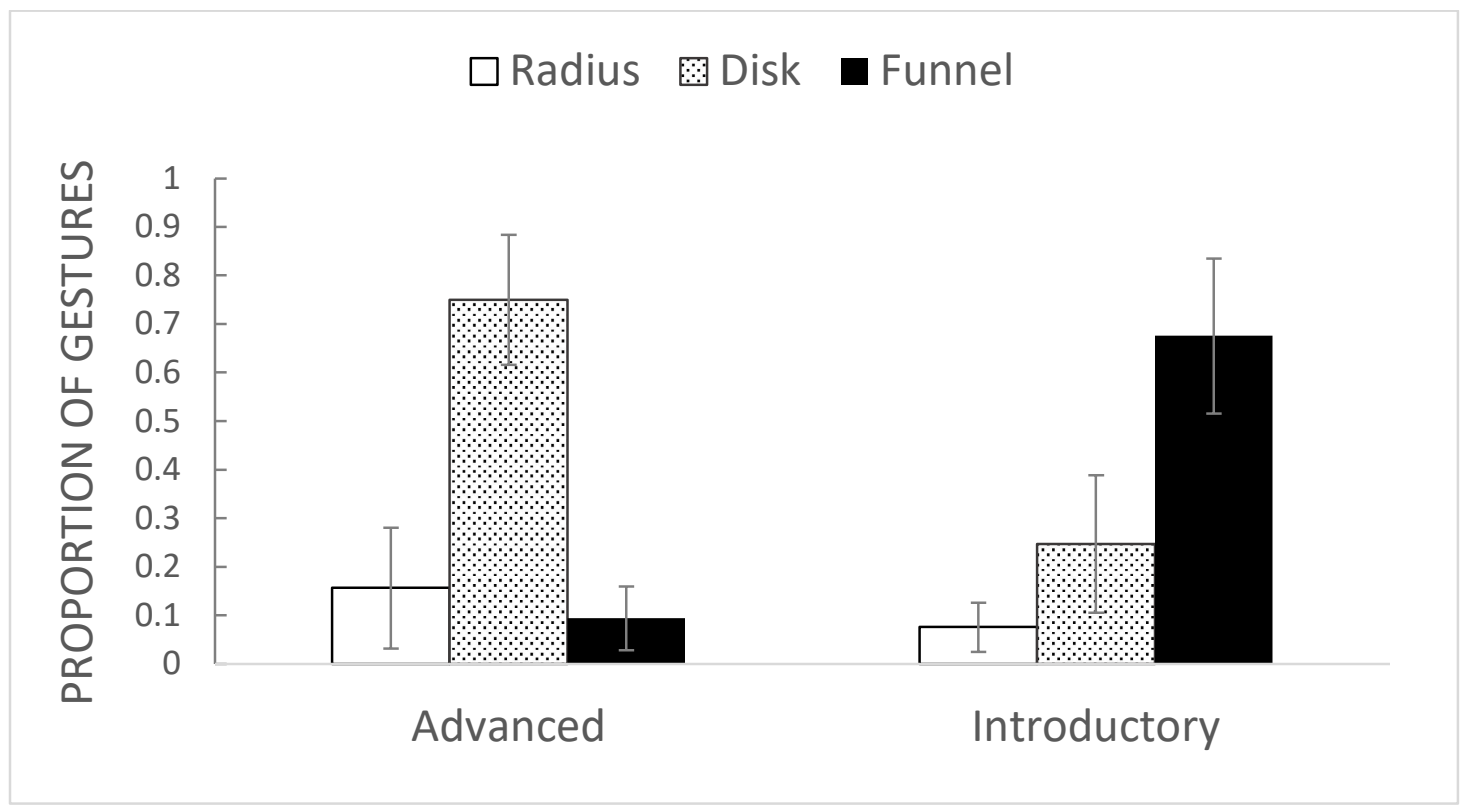




\section{Figure 7}

The Average Proportions of Speech in Three Categories of Processes of Change

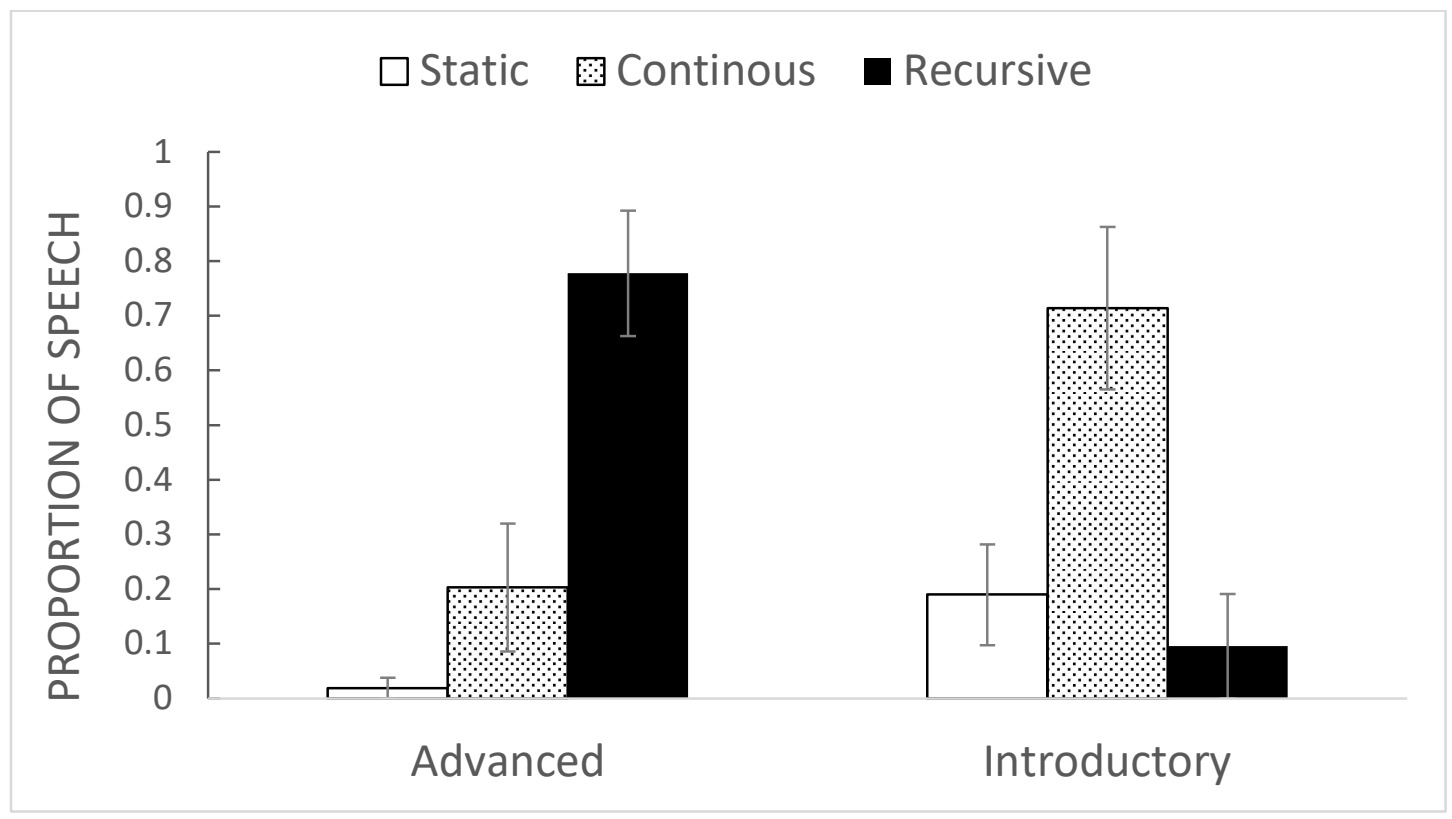




\section{Figure 8}

The Average Proportions of Gestures in Three Categories of Processes of Change

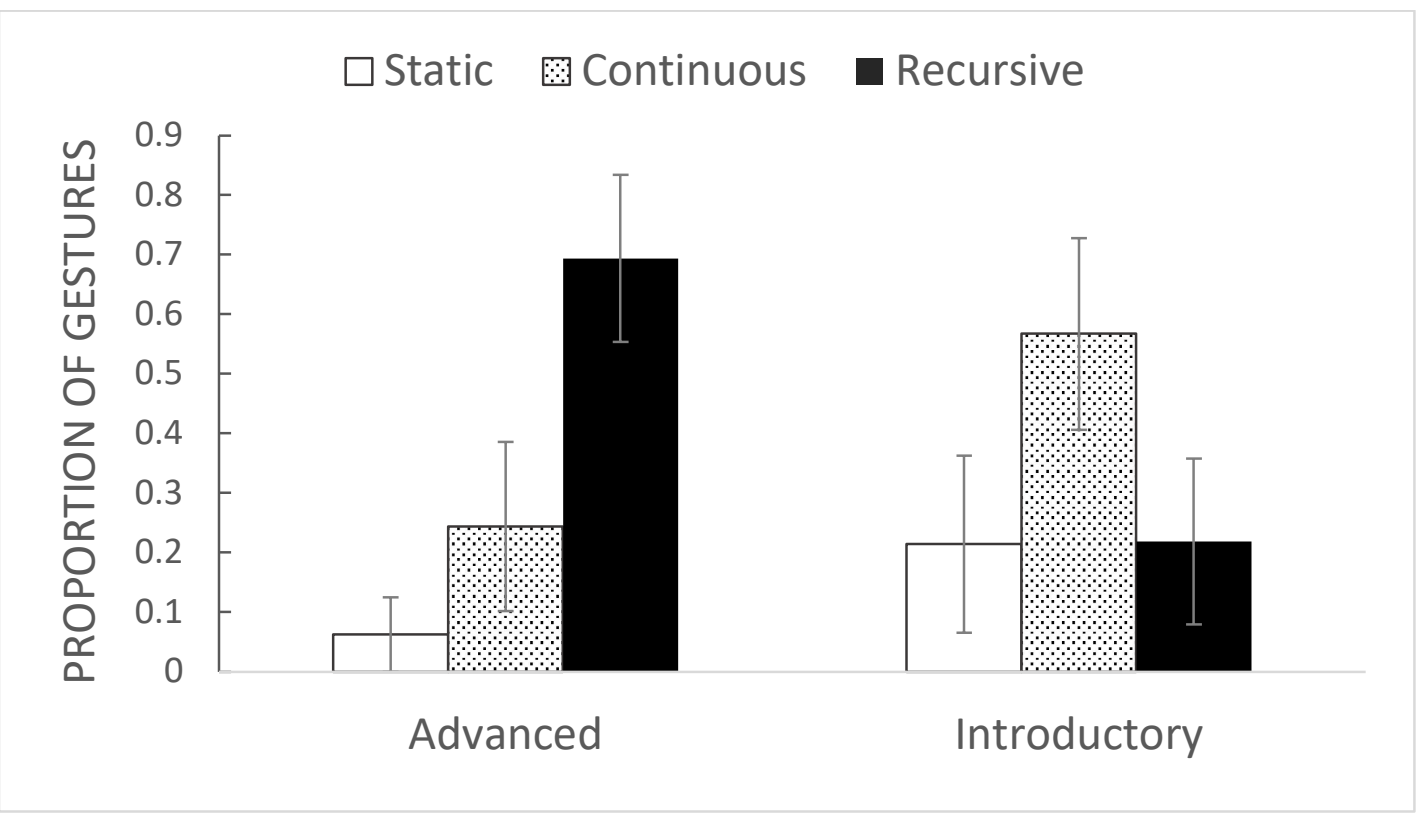




\section{List of Figure Captions}

Figure 1. Diagram of the Problem.

Figure 2. Three Possible Graphs of the Rate of Change.

Figure 3. An Introductory Participant's Gesture.

Figure 4. An Advanced Participant's Gesture.

Figure 5. The Average Proportions of Speech in Three Categories of Objects of Change.

Figure 6. The Average Proportions of Gestures in Three Categories of Objects of Change.

Figure 7. The Average Proportions of Speech in Three Categories of Processes of Change.

Figure 8. The Average Proportions of Gestures in Three Categories of Processes of Change. 